\title{
SVC WITH ANN CONTROLLER FOR A SUPERCONDUCTING GENERATOR
}

\author{
G. A. Morsy, R. A. Amer and H. A. Yassin \\ Electrical Engineering Department, Faculty of Engineering, \\ Minoufiya University, Shebin El-Kom, Egypt
}

\begin{abstract}
This paper presents the design of an artificial neural network (ANN) controller for static var compensator (SVC) to improve the stability and the performance of a superconducting generator (SCG). The SVC is also equipped with conventional proportional integral derivative (PID) controller designed according to the pole placement technique. The ANN controller patterns are gathered from unsupervised (self learning) ANNs-PID using an optimization technique. These pattern groups are chosen to cover most operating conditions based on P-Q plane. The present control strategy is tested on a SCG connected to an infinite bus system. To achieve a high degree of accuracy, the system is represented by a detailed non-linear model including the SCG, SVC, the transmission system and non-linear constraints. The simulation results reveal that the proposed ANN-SVC controller achieves further enhancement of the system performance and stability over a wide range of operating conditions and under sever disturbances compared with conventional PIDSVC controller.

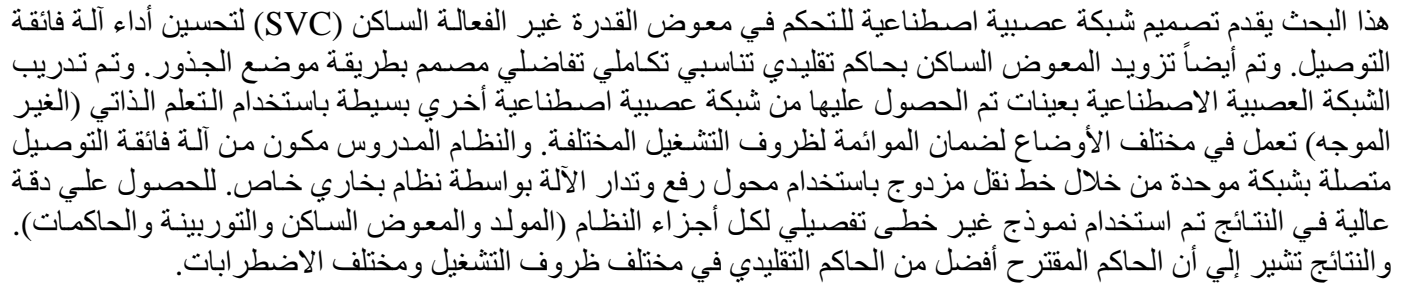

Keywords: Power system control, Superconducting generator, Static var compensator, ANN control.

\section{INTRODUCTION}

Superconducting generators (SCGs) have many advantages over conventional synchronous machines as the capability of generating greater power with higher efficiency [1, 2]. Also, SCGs have additional economic benefits as possibility of generation at transmission line voltages, reduced size and weight as well as environmental advantages due to reduced oil consumption and $\mathrm{CO} 2$ emissions [3]. In view of control, the SCG requires a special attention and more considerations due to the field winding zero resistance and the corresponding extreme long time constant, which makes the SCG excitation control is not effective [4, 5]. Hence, the governor control loop is the only permissible control loop for the system performance enhancement.

Static var compensator (SVC) has been widely used in power systems for voltage support, transient stability enhancement and power system oscillation damping [6, 7]. Various conventional controllers have been employed for SVC such as lead-lag compensator and PID [8]. These conventional controllers are fixed parameters and can insure good performance under a certain operating condition but, may be not suitable for other conditions. To maintain a better performance under a wide range of operating conditions, self tuning adaptive controllers have been developed [9].

Since 1989, ANNs methodology has captured interest in electrical power engineering and has promised to ensure effective system performance enhancement $[10,11]$. Among of the ANN advantages, rapidity due to the parallel mechanism, the memorization ability, robustness, fault tolerance and adaptability. 


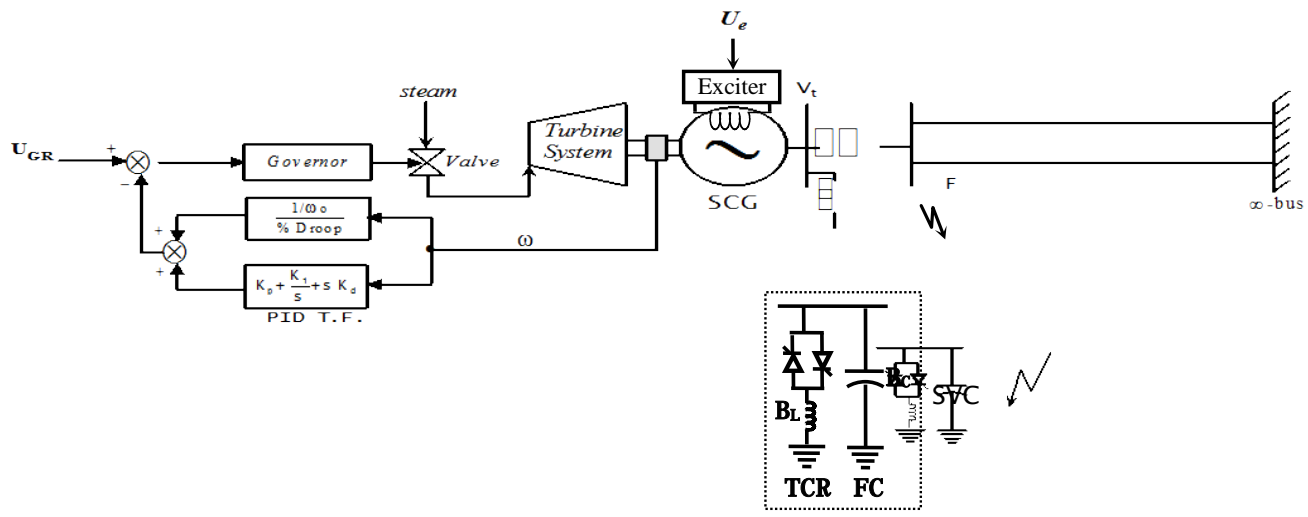

Fig. 1 The studied electrical power system

This paper presents an alternative control approach using the ANN control strategy for SVC to improve the performance of the complex structure, low inherent damping and the high hunting frequency SCG. The ANN scheme was trained by on-line simple unsupervised (self learning) ANN-PID using an optimization technique to minimize the system deviations in most operating conditions. The simulation results illustrate that, the ANN controller is more flexible and robust for the system when subjected to various disturbances in a wide range of operating conditions compared with conventional PID controller.

\section{POWER SYSTEM MODELING}

The considered power system consists of a SCG connected to an infinite bus through a double circuit transmission line using a step-up transformer. The SCG is driven by a three stages steam turbine system with reheat and fast acting electro-hydraulic governor. In addition to that, a SVC connected at the SCG terminals via a step-down transformer as shown in Fig. 1.

A digital SIMULINK model has been built to simulate the studied system and is tested after normal operation of $200 \mathrm{~ms}$ [12]. The SVC mathematical model is described in Appendix A and the system parameters are mentioned in Appendix B.

The performance of the SCG is improved by incorporating controllers in the governor loop such as phase advance network and PID controller [4]. The used controller in this paper is the PID controller. The PID controller transfer function is given by:

$$
\mathrm{H}(\mathrm{s})=\mathrm{K}_{\mathrm{p}}+\frac{\mathrm{K}_{\mathrm{i}}}{\mathrm{s}}+\mathrm{s} \mathrm{K}_{\mathrm{d}}
$$

where, $\mathrm{Kp}, \mathrm{Ki}$ and $\mathrm{Kd}$ are the PID controller parameters.

The PID parameters are determined using Pole placement technique and their values are reported in Appendix B [13].

\section{SVC CONTROLLERS}

One of the major reasons for installing a SVC is to improve dynamic voltage control and thus increases system load-ability. The SVC is equipped either by conventional controller (lead-lag compensator, PID, etc) or adaptive controller (fuzzy logic, ANN, etc) to set the firing angle value of the thyristors and hence the SVC shunt susceptance setting [14]. In this study, the conventional controller used is the PID and the adaptive one is the ANN. Selector is used to connect the desired controller to the SVC as shown in Fig. 2.

\subsection{PID Controller for SVC}

The PID controller is relatively simple in practical implementation and can enhance the system performance particularly to minimize post fault oscillations. The PID controller transfer function for SVC is:

$\mathrm{H}_{\mathrm{svc}}(\mathrm{s})=\mathrm{K}_{\mathrm{ps}}+\frac{\mathrm{K}_{\mathrm{is}}}{\mathrm{s}}+\mathrm{sK}_{\mathrm{ds}}$

Where, $K_{p s}, K_{i s}$ and $K_{d s}$ are the PID-SVC controller parameters.

Pole placement technique is used in order to determine the controller parameters which requires the system linearized model $[4,8]$. The selected roots are $-4.5 \pm \mathrm{j} 15$ and -0.001602 for SCG rotor and field respectively at lagging p.f. The dominant eigenvalues of the system with PID-SVC compared with the SVC-voltage regulator only are illustrated in Table 1. From the pole placement technique the calculated values of Kps, Kis and Kds are 1.0532, 0.4332 and 0.0385 respectively. 


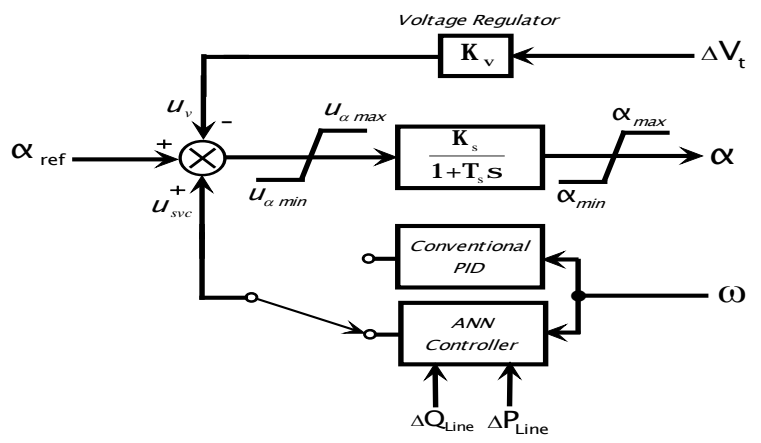

Fig. 2 the SVC firing angle control system

Table 1 The system dominant eigenvalues

\begin{tabular}{|l|c|c|}
\hline \multirow{2}{*}{ Modes } & \multicolumn{2}{|c|}{ At lagging p.f. } \\
\cline { 2 - 3 } & PID-SVC controller & voltage regulator only \\
\hline Rotor & $-4.5 \pm \mathrm{j} 15$ & $-3.868 \pm \mathrm{j} 15.228$ \\
\hline Field & -0.001602 & -0.00160153 \\
\hline
\end{tabular}

\subsection{Ann Networks}

This section presents two different groups of ANNs. The first group is designed to obtain the pattern groups which, are used in training the second ANNs group.

\subsubsection{The Simple ANN-PID}

To obtain the values of PID parameters a simple ANN is established to control the system with weights and biases adjustment. The ANN parameters adjustment is done by minimizing the system performance index, which indicates the system deviation. The system performance index (p.index), which is the total sum of the system deviations multiplied by the square of time as:

p. i ndex $=\int_{0}^{\infty} \mathrm{e}(\mathrm{t}) * \mathrm{t}^{2}$

Where, e(t) $=\Sigma$ \{deviations in speed, rotor angle, valve position and the SCG terminal voltage amplitude $\}$, $\mathrm{t}$ : is the time.

The purpose of the simple ANN-PID net is to generate patterns at various conditions. the implementation of optimized ANN-PID controller that uses on-line tuning of the PID parameters based on an optimization technique that minimizes the system deviations of the normal values [15]. The minimization of the performance index is implemented by the use of MATLAB optimization toolbox. The inputs of the simple ANN are the deviation in the transmission line active and reactive powers and its output is only one PID parameter as $\mathrm{Kps}$, Kis or Kds so, the simple ANN is repeated three times one for each controller parameter. Fig. 3 shows the construction of one net of these ANN groups, which consists of one input layer, one hidden layer (2-neurons) with a hyperbolic tangent sigmoid activation function and one output with a pureline activation function.

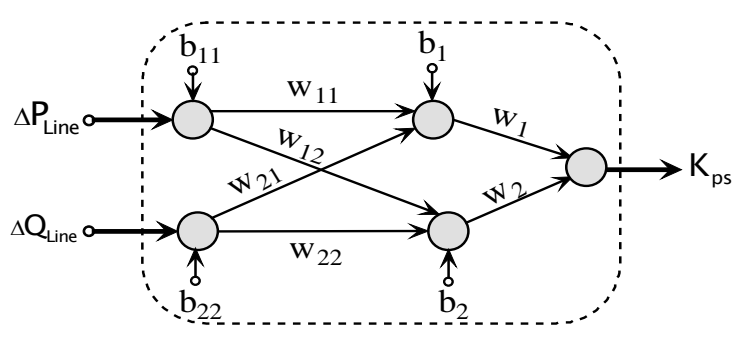

Fig. 3 The architecture of one on-line simple ANN-PID

These ANN parameters are tuned at different operating conditions according to performance index minimization at each case. Now, several values of $\mathrm{Kps}$, Kis and Kds ,according to the deviation in the transmission line active and reactive powers, are obtained. These groups of patterns are shown in Fig. 4.

\subsubsection{The Proposed ANN Controller}

Another ANN is established to be trained on the results of the first simple ANN patterns. The second ANN, which is used for system control, consists of one input layer, first hidden (20-neurons) with hyperbolic tangent sigmoid activation function, second hidden layer (10- neurons) with log sigmoid activation function and one output layer with a pureline activation function. Also, three ANNs are used, one for each controller parameter. The architecture of one of these ANNs is shown in Fig. 5. The complete ANN controller system is illustrated in Fig. 6.

\section{ANN TRAINING}

The Levenberg-Marquardt algorithm is used as back propagation technique to train the second ANN groups on the result patterns of the simple ANNs [13]. The training of PID parameters against epochs is shown in Fig. 7, this figure illustrates that each parameter reaches the goal.

\section{SIMULATION RESULTS}

The proposed ANN-SVC controller has been implemented and the system performance examined for various types of disturbances at different operating conditions. To illustrate the effectiveness of the proposed ANN-SVC controller, a fairly detailed non-linear model of the system is used and the simulation results are compared with conventional PID-SVC controller. The system's response for a symmetrical three-phase short circuit at one line of the two lines beside the transformer high voltage side for $120 \mathrm{~ms}$ duration is shown in Fig. 8. 


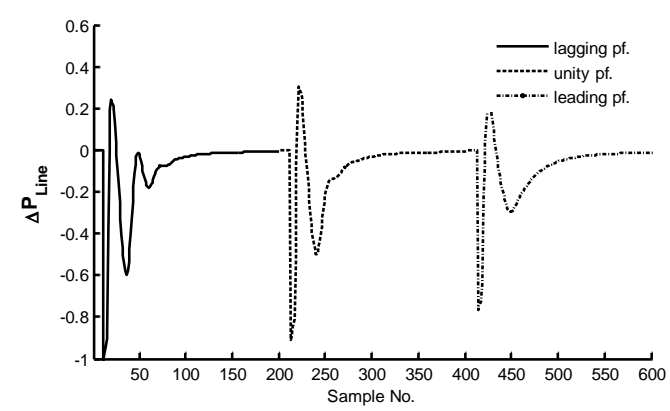

(a) First input patterns

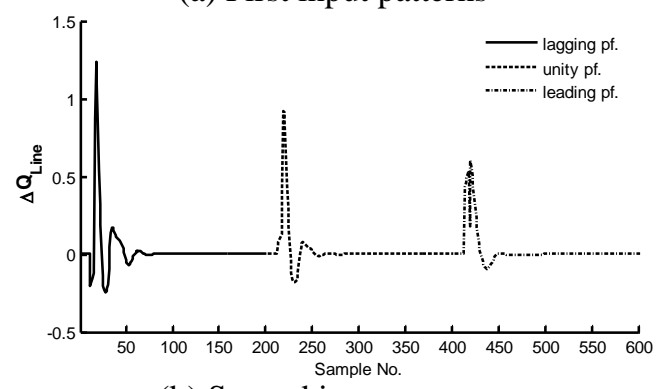

(b) Second input patterns

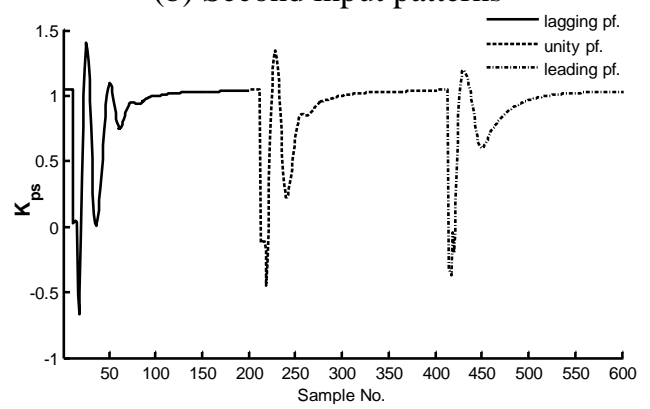

(c) First output patterns

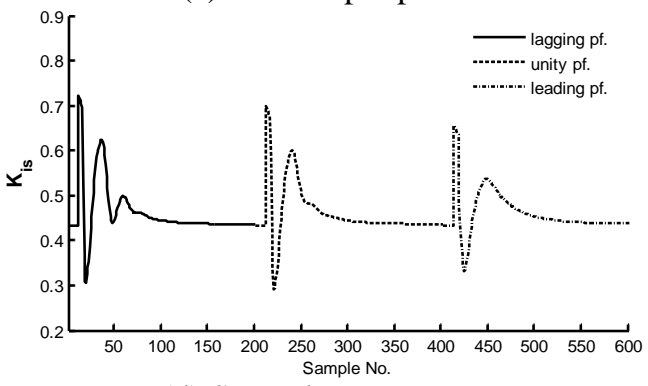

(d) Second output patterns

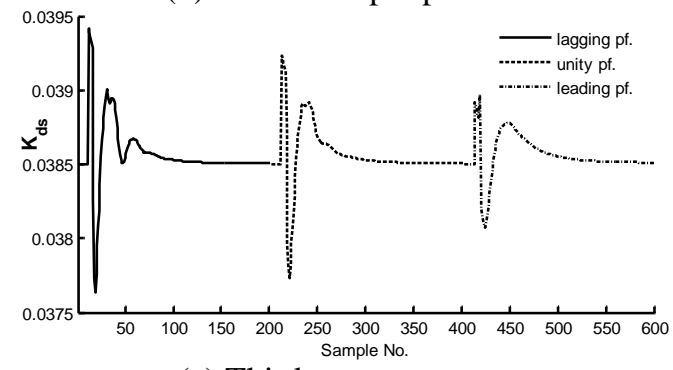

(e) Third output patterns

Fig. 4 The simple ANN-PID pattern groups
The response of the system for a symmetrical three-phase short circuit for $277 \mathrm{~ms}$ and $280 \mathrm{~ms}$ duration is shown in Figs $(9,10)$ respectively. Also, Fig. 11 shows a symmetrical three-phase short circuit for $120 \mathrm{~ms}$ duration followed by one line outage of the two transmission line for $200 \mathrm{~ms}$ response. These results illustrate that, the ANN controller is more reliable than conventional controller as it provides a good damping to the electro-mechanical modes of oscillations and all system variables quickly return to their initial values.

\section{CONCLUSION}

The paper presents an ANN-SVC methodology based PID-SVC controller as an alternative approach to improve the performance and the stability limits of the low inherent damping characteristics and the high hunting frequency SCG that equipped with conventional PID controllers in the governor loop. The data patterns are obtained from simple ANN-PID system trained on-line to overcome the conventional controllers fixed parameters problem. The used technique consists of two operations, the first operation is to obtain the pattern groups by simple on-line ANN and the second operation is to train the proposed ANN on the obtained patterns. So, this study uses two types of ANNs. The second trained ANN controller is the used one to control the system. The SVC is controlled either by conventional PIDSVC or by ANN-SVC controllers. The simulation results show the adaptability, reliability and the effectiveness of the ANN-SVC controller over the conventional controller for various disturbances and at a wide range of operating conditions in terms of damping increase, system variables fast return to their initial values.

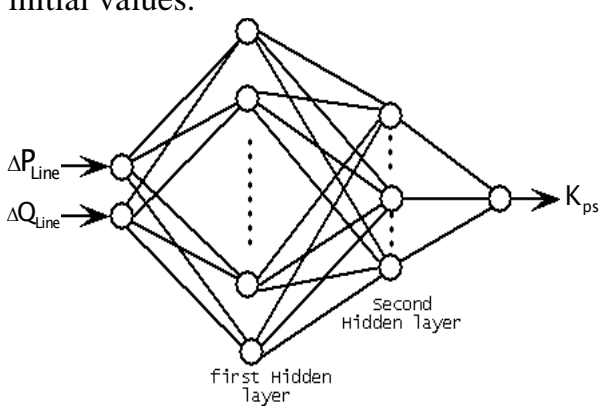

Fig. 5 The architecture of one ANN

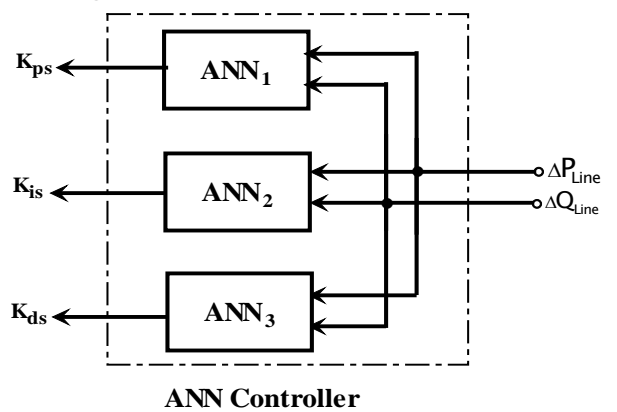

Fig. 6 The ANN controller with all components 


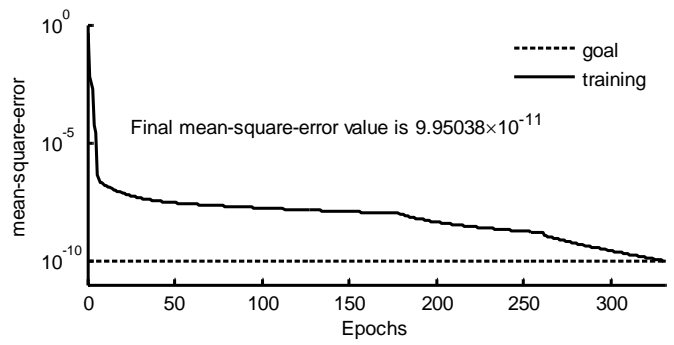

(a) $K_{p s}$ Training

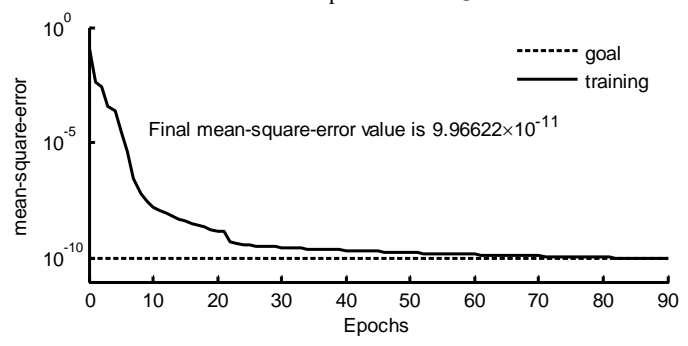

(b) $\mathrm{K}_{\mathrm{is}}$ Training

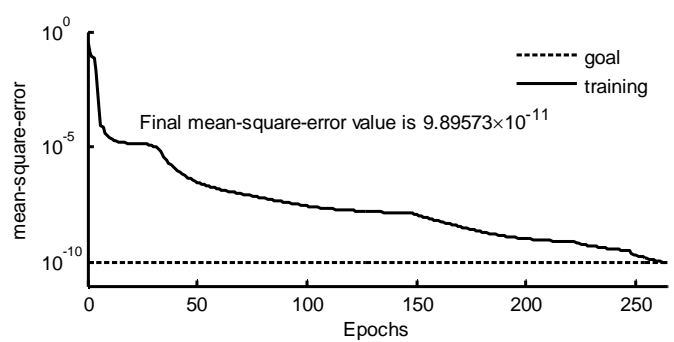

(c) $\mathrm{K}_{\mathrm{ds}}$ Training

Fig. 7 The training of PID parameters

\section{REFERENCES}

[1] S. M. Osheba et al, "Comparison of transient performance of superconducting and conventional generators in a multimachine system”, IEE-Proc. 135, pt. C, No. 5, Sept. 1988, pp.389-395.

[2] K. Yamagushi, et al, "Rotor design of a 1000 MW superconducting generator”, IEEE Trans. on EC, Vol. 4, No. 2, June 1989.

[3] H. A. Khattab, "Stabilization of A Superconducting Generating Unit In A Multimachine System”, Ph.D. Thesis, Menoufia University, Faculty of Eng. 2007.

[4] G. A. Morsy, H. A. Kattab and A. Kinawy, "Design of a PI controller for a superconducting generator", Eng. Research. Vol. 23, No. 1, Fac. of Eng., Men., Univ., pp. 61-77, January 2000.

[5] H. A. Khattab, "Control and Performance Analysis of A Superconducting Generator", M.Sc. thesis, Faculty of Eng., Men., Univ, 2000.

[6] V. K. Sood, "HVDC and FACTS Controllers: Applications of Static Converters in Power Systems”, Book published by Kluwer Academic press, e- ISBN: 1-4020-7891-9, 2004.
[7] X. P. Zhang, C. Rehtanz and B. Pal, "Flexible AC Transmission Systems: Modelling and Control”, ISBN-10 3-540-30606-4, SpringerVerlag Berlin Heidelberg, 2006.

[8] Y. Y. Hsu and C. J. Wu, "Design of PID Static VAR Controllers for The Damping Of Subsynchronous Oscillations", submitted to IEEE/PES summer meeting 1987.

[9] G. P. Chen, O. P. Malik, et al, “An Adaptive power system stabilizer based on the selfoptimizing pole shifting control strategy”, submitted to IEEE/PES winter meeting 1993.

[10] K.A. Ellithy and S.M. Al-Alawi, “Tuning a static var compensator controller over a wide range of load models using an artificial neural network”, EPSR, Vol. 38, pp.977-104, 1996.

[11]Y. Zhang et al, "An artificial neural network based adaptive power system stabilizer”, IEEE Trans. on EC-8. No. 1, pp. 71-77, March 1993.

[12] M. A. Alyan and Y. H. Rahim, "The role of governor control in transient stability of superconducting turbogenerators”, IEEE Trans. EC-2, March 1987, pp.38-46.

[13] G. A. Morsy, R. A. Amer and H. A. Yassin, “A New Unsupervised ANN Based PID Controller for a Superconducting Generator”, Eng. Research. Fac. of Eng., Men., Univ., Vol. 30, No. 4, October 2007, pp.409-416.

[14]Q. Gu, A. Pandey and S. K. Starrett, "Fuzzy logic control schemes for static VAR compensator to control system damping using global signal”, Electric Power Systems Research 67 (2003), pp.115-122.

[15] R. A. Saleh, "Genetic algorithm- Tuned Fuzzy Logic- Based Governor Controller For A Fully Superconducting Generator”, MEPCON'2003, Men. Univ., Dec.16-18, 2003.

\section{APPENDICES}

\section{Appendix A}

SVC Model:

In this study, the SVC is equivalent to variable susceptance and its equivalent circuit is shown in Fig. (A-1).

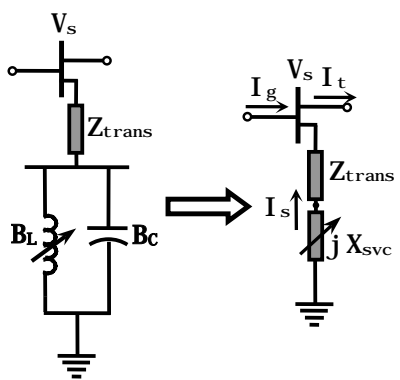

Fig. (A-1) The SVC equivalent circuit

Based on $d-q$ axes rotate with the SCG rotor speed, the SVC nonlinear first-order differential equations could be: 
G. A. Morsy, R. A. Amer and H. A. Yassin, " SVC with ANN Controller for a Superconducting ..."

${\stackrel{\square}{I_{s d}}}_{1}=\frac{\omega_{0}}{X_{s}}\left(-d t_{d}-I_{s d} R_{s}+I_{s q} X_{s}\right)+{ }_{s q}$

$\stackrel{\square}{I}_{s q}=\frac{\omega_{0}}{X_{s}}\left(-\Phi I_{t q}-I_{s q} R_{s}-I_{s d} X_{s}\right)-{ }_{s d}$

$\stackrel{\square}{\alpha}_{\mathrm{svc}}=\frac{\mathrm{K}_{\mathrm{s}}\left(\alpha_{\mathrm{ref}}+u_{s v c}-u_{v}\right) \alpha_{\mathrm{svc}}}{\mathrm{T}_{\mathrm{s}}}$

where, $X_{s}=X_{\text {trans }}+X_{\text {svc }}, R_{s}=R_{\text {trans }}, Z_{\text {trans }}=R_{\text {trans }}+j X_{\text {trans }}$

$\mathrm{X}_{\mathrm{svc}}=\frac{-1}{\mathrm{~B}_{\mathrm{C}}-\mathrm{B}_{\mathrm{L}}}, \mathrm{B}_{\mathrm{L}}=\mathrm{B}_{\mathrm{Lo}} \frac{2 \pi+\sin 2 \alpha-2 \alpha}{\pi}, \mathrm{I}_{\mathrm{t}}=\mathrm{I}_{\mathrm{g}}+\mathrm{I}_{\mathrm{s}}$.

\section{Appendix B}

Superconducting Generator Parameters:

2000 MVA, $1700 \mathrm{MW}, 3000 \mathrm{rpm}$

$\mathrm{X}_{\mathrm{d}}=\mathrm{X}_{\mathrm{q}}=0.5457$ p.u., $\mathrm{X}_{\mathrm{D} 1}=\mathrm{X}_{\mathrm{Q} 1}=0.2567$ p.u.

$\mathrm{X}_{\mathrm{D} 2}=\mathrm{X}_{\mathrm{Q} 2}=0.4225$ p.u., $\mathrm{X}_{\mathrm{f}}=0.541$ p.u., $\mathrm{R}_{\mathrm{a}}=0.003$ p.u.

$\mathrm{X}_{\mathrm{fd}}=\mathrm{X}_{\mathrm{fD} 1}=\mathrm{X}_{\mathrm{dD} 1}=\mathrm{X}_{\mathrm{dD} 2}=\mathrm{X}_{\mathrm{D} 1 \mathrm{D} 2}=0.237$ p.u.

$\mathrm{X}_{\mathrm{qQ1}}=\mathrm{X}_{\mathrm{qQ} 2}=\mathrm{X}_{\mathrm{Q} 1 \mathrm{Q} 2}=0.237$ p.u., $\mathrm{X}_{\mathrm{fD} 2}=0.3898$ p.u.

$\mathrm{R}_{\mathrm{D} 1}=\mathrm{R}_{\mathrm{Q} 1}=0.1008$ p.u., $\mathrm{R}_{\mathrm{D} 2}=\mathrm{R}_{\mathrm{Q} 2}=0.00134$ p.u.
Field time constant=750 sec., H=3 KW.s/KVA

Transmission line parameters:

$\mathrm{X}_{\mathrm{T}}=0.15$ p.u., $\mathrm{R}_{\mathrm{T}}=0.003$ p.u., $\mathrm{X}_{\mathrm{L}}=0.05$ p.u., $\mathrm{R}_{\mathrm{L}}=0.005$ p.u.

Turbines And Governor System Parameters:

$\mathrm{T}_{\mathrm{HP}}=\mathrm{T}_{\mathrm{GM}}=0.1 \mathrm{~s}, \mathrm{~F}_{\mathrm{HP}}=26 \%, \mathrm{~T}_{\mathrm{IP}}=0.1 \mathrm{~s}, \mathrm{~F}_{\mathrm{IP}}=42 \%$

$\mathrm{T}_{\mathrm{LP}}=0.3 \mathrm{~s}, \mathrm{~F}_{\mathrm{LP}}=32 \%, \mathrm{~T}_{\mathrm{HR}}=10 \mathrm{~s}, \mathrm{P}_{\mathrm{o}}=1.2$ p.u.

SCG's PID Controller Parameters:

$\mathrm{K}_{\mathrm{p}}=0.1827, \mathrm{~K}_{\mathrm{i}}=0.0001257, \mathrm{~K}_{\mathrm{d}}=0.0723$

\section{SVC Parameters:}

$\mathrm{R}_{\text {trans }}=0.01$ p.u., $\mathrm{X}_{\text {trans }}=0.145$ p.u., $\mathrm{B}_{\mathrm{C}}=\mathrm{B}_{\mathrm{Lo}}=1.0$ p.u. $\alpha_{\text {svco }}=90^{\circ}, \quad 60^{\circ} \leq \alpha_{\text {svc }} \leq 135^{\circ}, \quad K_{s}=1, T_{s}=0.05$ sec., $\left|\mathrm{u}_{\alpha}\right|=10, \mathrm{~K}_{\mathrm{v}}=50$.
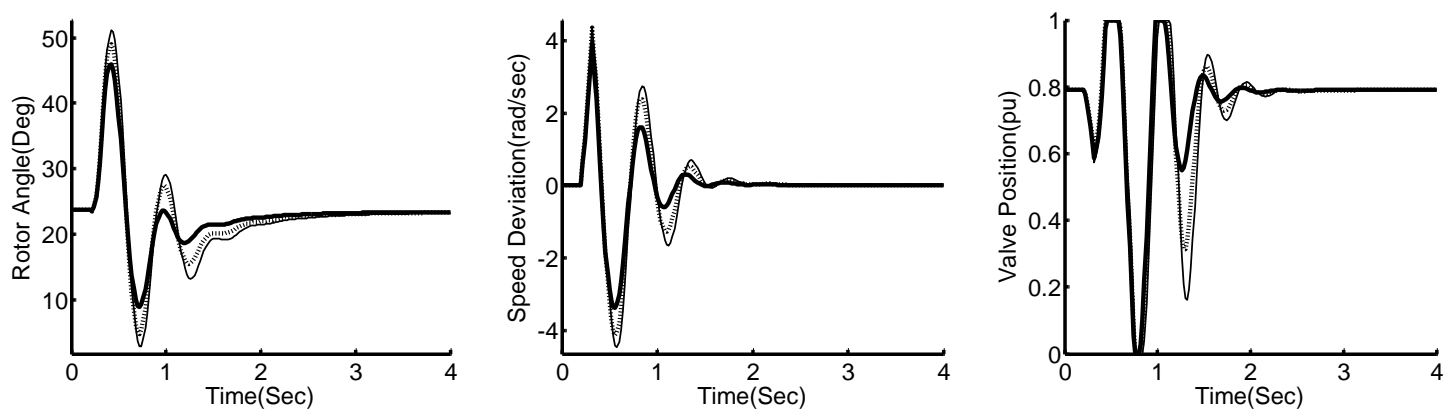

Fig. 8 System response to a 3-phase short circuit for $120 \mathrm{~ms}$ at lagging p.f.
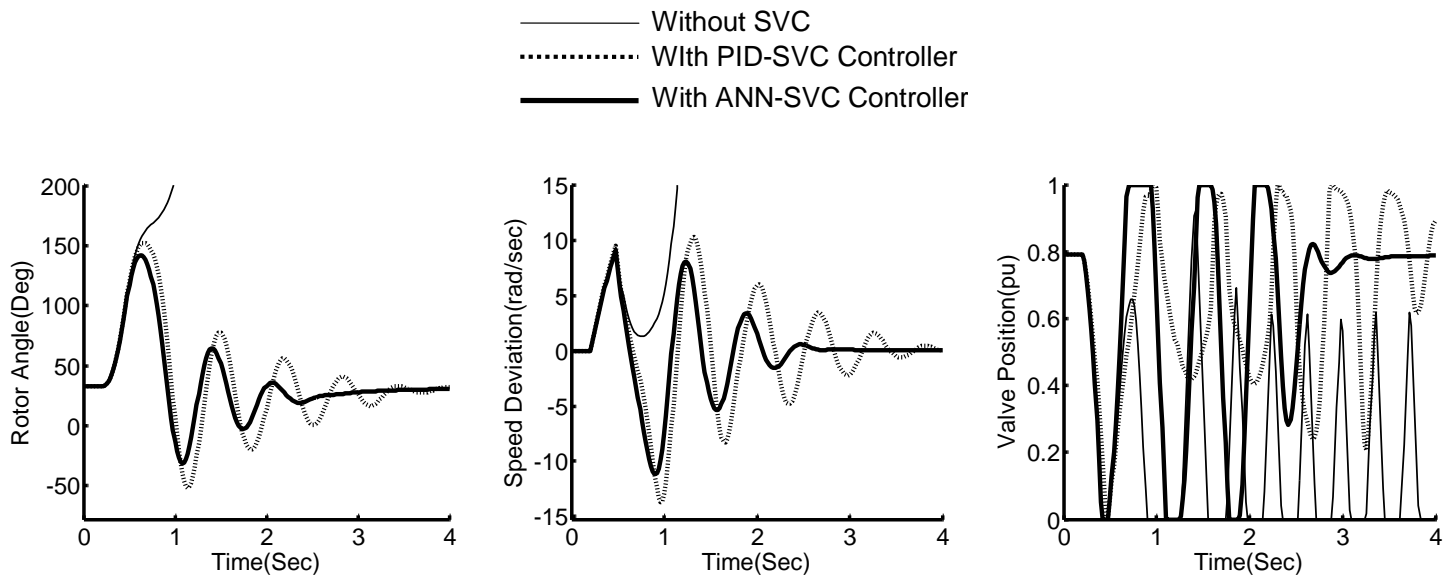

Fig. 9 System response to a 3-phase short circuit for $277 \mathrm{~ms}$ at unity p.f.

- Without SVC

.............. WIth PID-SVC Controller

With ANN-SVC Controller 

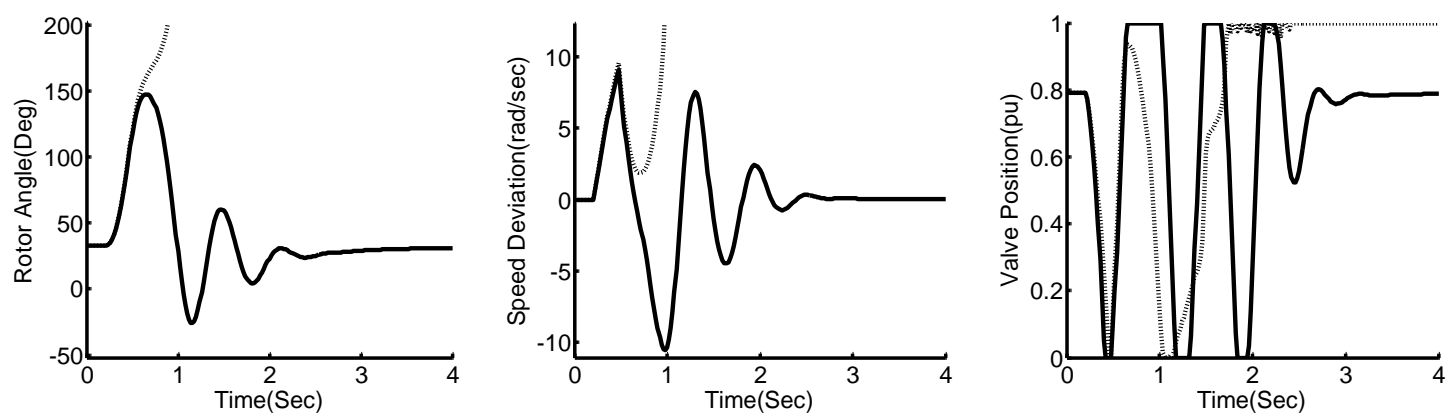

Fig. 10 System response to a 3-phase short circuit for 280 ms at unity p.f.

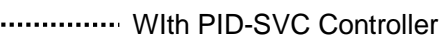
With ANN-SVC Controller
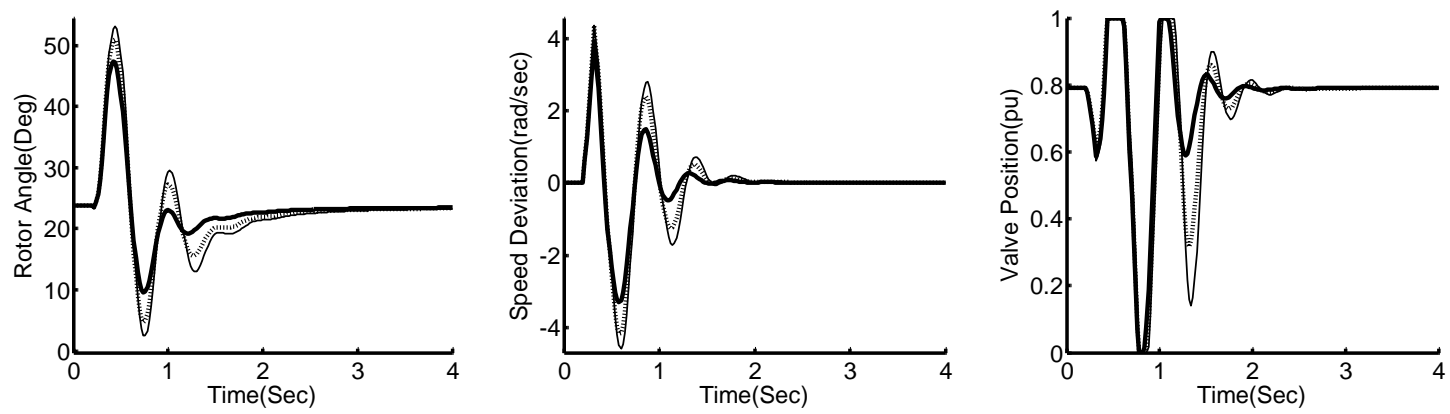

Fig. 11 System response to 3-phase short circuit for $120 \mathrm{~ms}$ followed by one line outage for $200 \mathrm{~ms}$ at lagging p.f.

Without SVC

WIth PID-SVC Controller

With ANN-SVC Controller 